\title{
ETNOCONHECIMENTOS SOBRE ANIMAIS DE PESCADORES ARTESANAIS NA AMAZÔNIA COSTEIRA PARAENSE
}

\author{
Claudia Nunes Santos ${ }^{1}$
}

\begin{abstract}
RESUMO
A diversidade faunística, bem como a diversidade humana da Amazônia tem sido estudada por diversos especialistas em busca da compreensão das formas de vida e evolução do sistema. Para superarmos os limites das interpretações produzidas, além de unirmos diferentes ferramentas, técnicas e abordagens das diversas disciplinas da ciência, precisamos considerar as subjetividades pertencentes a este complexo. Os conhecimentos locais, tradicionais ou etnoconhecimentos dos diferentes povos e comunidades ampliam a visão sobre a sociobiodiversidade da região. Um dos esforços que orientam a Etnobiologia é a ruptura como um modo de fazer ciência, que separa sociedade e natureza, bem como a compreensão de que o conhecimento é construído na relação entre pessoas pesquisadas e que pesquisam. Apresento aqui algumas inferências conservacionistas das interações entre pescadores com tartarugas marinhas e aves costeiras. As pesquisas foram realizadas entre 2015 e 2018, em seis comunidades de pescadores nos municípios Bragança, Tracuateua e Salinópolis, no estado do Pará. As ricas etnozoologias e etnotaxonomias de pescadores artesanais sobre tartarugas-marinhas e aves-costeiras locais revelam um conhecimento aprofundado sobre estes animais que não são de interesse para o autossustento. E ainda, a consciência dos pescadores quanto à importância dos animais para os ecossistemas são etnoconhecimentos importantes para o entendimento das relações humanos-animais, bem como para ações de preservação e manejo localmente referenciadas.
\end{abstract}

Palavras-chave: Conhecimentos tradicionais. Etnozoologia. Tartarugas. Aves.

\section{ARTISANAL FISHERMEN ETHNO-KNOWLEDGE REGARDING ANIMALS IN THE COASTAL AMAZON OF PARÁ}

\begin{abstract}
The fauna diversity, as well as the human diversity, in Amazon has been studied by several specialists in search of understanding the life and evolution of this system. To overcome the limits of interpretations produced, besides using different tools, techniques and approaches from different scientific disciplines, it is necessary to consider the subjectivities pertaining to this complex. Local, traditional, or ethnoknowledge of different peoples and communities broadens the view on the socio-biodiversity. One effort that guide Ethnobiology is the break with a way of do research that separates society and nature, as well as the understanding that knowledge is built in the relationship between people researched and who research. Here, I present some conservationist inferences about interactions between fishermen with sea turtles and coastal birds. The surveys were carried out between 2015 and 2018, in six fishing communities in the municipalities of Bragança, Tracuateua and Salinópolis, in the state of Pará. The rich ethnozoologies and ethnotaxonomies of artisanal fishermen on local sea turtles and coastal birds, reveal a profound knowledge about these animals that are not of self-support or economic interest. Furthermore, fishermen's awareness of the importance of animals to ecosystems is an important ethnoknowledge for understanding human-animal relations, as well as for locally referenced preservation and management actions.
\end{abstract}

Keywords: Traditional knowledge. Ethnozoology. Turtles. Birds.

\footnotetext{
${ }^{1}$ Professora Adjunta no Departamento de Biologia da Universidade Federal de Sergipe. Membro dos grupos de pesquisa "Estudos Socioambientais Sosteiros" e "Etnobiologia e Patrimônio Biocultural", ambos cadastrados no CNPq. Sócia Efetiva da Sociedade Brasileira de Etnobiologia e Etnoecologia e Colaboradora da Associação Brasileira de Antropologia. E-mail: cnunes@academico.ufs.br.
} 
Data de submissão: 13.10 .2020

Data de aprovação: 01.12 .2020

\section{INTRODUÇÃO}

Os conhecimentos tradicionais são o resultado de uma coevolução entre as sociedades e seus ambientes naturais. Esta evolução simultânea permitiu a conservação de um equilíbrio no qual o manejo dos recursos, bióticos e abióticos, está diretamente relacionado com mitos, lendas, regras, valores e saberes. Este entendimento de que a diversidade cultural caminha lado a lado com a diversidade ecológica e que uma depende da outra é crescente. Entretanto, o etnocentrismo predominante na construção do conhecimento científico, não favorece o reconhecimento dos sistemas de saberes organizados de outras culturas (DIEGUES, 2000).

No Brasil, o Decreto Federal 6040 instituiu, em 27 de fevereiro de 2007, a Política Nacional de Desenvolvimento Sustentável dos Povos e Comunidades Tradicionais (PNPCT), definindo-os, em seu artigo $3^{0}$, parágrafo 1 , como:

grupos culturalmente diferenciados e que se reconhecem como tais, que possuem formas próprias de organização social, que ocupam e usam territórios e recursos naturais como condição para sua reprodução cultural, social, religiosa, ancestral e econômica, utilizando conhecimentos, inovações e práticas gerados e transmitidos pela tradição. (BRASIL, 2007, p. 1).

Estes, também denominados saberes tradicionais, conhecimento ecológico local ou etnoconhecimentos, são adquiridos através de observações extensivas dos elementos naturais e transmitidos por via oral, de geração a geração (BERKES et al., 2000; HUNTINGTON, 2000). $\mathrm{O}$ resgate desses saberes empíricos, visando incluí-los nas estratégias de desenvolvimento socioambiental se dá a partir da construção de pontes entre as disciplinas tradicionais da academia e as diversas culturas.

Uma destas pontes, a etnobiologia, investiga as relações do homem com os seres vivos e com o mundo natural (MARQUES, 1991). Dentro desta, a etnozoologia é definida como um estudo transdisciplinar dos pensamentos e percepções (mitos e crenças), dos sentimentos (representações afetivas) e dos comportamentos (ações) que constituem as relações entre populações humanas e os animais que as cercam (MARQUES, 2002). Portanto, a etnozoologia traduz-se como o estudo da ciência zoológica do "outro", por ser construída a partir do referencial teórico acadêmico, levando em consideração as perspectivas culturais de cada grupo humano (CAMPOS, 1994).

Meu interesse pelos conhecimentos tradicionais foi desenvolvido à medida que eu submergia, enquanto Bióloga em busca da diversidade zoológica, em diferentes contextos socioambientais. Despertou nos primeiros contatos com agricultores do entorno do Parque Nacional Serra de Itabaiana (Sergipe). Intensificou durante as expedições às várzeas do aluvião entre os rios Solimões e Japurá (Amazonas), onde foi implantada a Reserva de Desenvolvimento Sustentável Mamirauá, quando tive muitos encontros com ribeirinhos pescadores e indígenas. Aprofundou-se nos manguezais da Amazônia costeira paraense (Reserva Extrativista Marinha (RESEX-MAR) Caeté-Taperaçu, RESEX-MAR Tracuateua e arredores) onde convivi com pescadores artesanais, extrativistas e agricultores. $\mathrm{O}$ olhar para as formas de vida e a escuta dos saberes desses grupos humanos transformaram minha atitude no mundo e a abordagem das minhas pesquisas. Passei a me dedicar ao entendimento das teias que envolvem homens e animais, a partir da perspectiva ética-êmica da etnozoologia.

Este artigo foi construído a partir de dados secundários de trabalhos desenvolvidos, de forma assíncrona, entre 2015 e 2018, com foco em grupos zoológicos diferentes em cada local de estudo (tartarugas-marinhas e aves). Os resultados foram aqui apreciados, visando ressaltar 
a contribuição dos etnoconhecimentos, de pescadores artesanais polivalentes na Amazônia costeira paraense, sobre animais marcantemente presentes nos locais de moradia e/ou pesca, para o entendimento da diversidade faunística. Bem como para a reflexão de questões ambientais e de manejo dos componentes animais.

\section{DIVERSIDADE ZOOLÓGICA E ETNOCONHECIMENTOS: A PERSPECTIVA DA ETNOZOOLOGIA}

Os estudos da etnozoologia incluem os sistemas empregados na classificação dos elementos presentes nos ecossistemas. Os quais, segundo Ellen (1986), refletem o modelo organizacional social de uma comunidade. Denominadas de etnotaxonomias, estas classificações relacionam os aspectos naturais mais notáveis aos humanos (cor, tamanho, forma do corpo, odor), bem como os aspectos de significância cultural (BROWN, 1986).

Kellert (1983) afirma que humanos percebem os animais nas formas de (1) intenção, (2) saber e/ou (3) simbólica. Dentre estas crenças, saberes e fazeres, a significância das diferentes espécies animais nos diversos conhecimentos tradicionais pode ser estudado, como nos instigam Vargas-Clavijo e Costa-Neto (2010), através da compreensão das atitudes humanas para com os demais animais. Em geral, os etnozoólogos se impressionam com a coerência dos saberes e práticas que as populações tradicionais possuem e demonstram, em graus diversos, sobre as espécies de animais com as quais convivem e interagem (POSEY, 1982; SCHEPS, 1993). Esses estudos contribuem, tanto para a elaboração de estratégias de manejo e conservação da fauna, quanto dos diversos simbolismos e representações, historicamente construídos nas diferentes culturas, sobre os animais.

Posey (1986, p. 16) recomendou aos etnobiólogos que não nos prendamos somente a dados estatisticamente relevantes, pois para ele

\footnotetext{
a contradição e a anomalia são os princípios culturais básicos a serem investigados em maior extensão. Nisto é que a Etnobiologia difere da Biologia, esta última trata os fenômenos socioculturais como dados estatisticamente irrelevantes, enquanto a Etnobiologia deve considerar a contradição e a anomalia como elementos fundamentais ao desenvolvimento dos métodos de pesquisa.
}

Assim, a continuidade entre conhecimentos tradicionais e conhecimentos científicos foi construída, nos estudos aqui compilados, utilizando múltiplos métodos e técnicas, na perspectiva quali-quantitativa. Esta triangulação é defendida por Ruediger e Riccio (2004) como uma estratégia para amenizar os possíveis vieses das pesquisas que envolvem as percepções humanas do mundo natural.

Para compreender as percepções de pescadores artesanais, em diferentes espaços/contextos da costa amazônica paraense, diferentes técnicas foram empregadas no registro e análises das histórias orais. A história oral centra-se na memória humana e sua capacidade de rememorar o passado enquanto testemunha do vivido. Podemos entender a memória como a presença do passado, como uma construção psíquica e intelectual de fragmentos representativos desse mesmo passado, nunca em sua totalidade, mas parciais em decorrência dos estímulos para a sua seleção. Não é somente a lembrança de certo indivíduo, mas de um indivíduo inserido em um contexto familiar ou social, por exemplo, de tal forma que suas lembranças são permeadas por inferências coletivas, moralizantes ou não (MATOS; SENNA, 2011).

As técnicas foram utilizadas seguindo a Metodologia Geradora de Dados, proposta por Posey (1986), que aponta importantes sugestões para um diálogo de campo em que os referenciais do "outro" sejam respeitados e, sobretudo, para que se compreendam os conceitos a partir da própria cosmologia e cosmogonia do grupo pesquisado. Nesta metodologia de coleta 
de dados, quanto mais abertas são as perguntas, maior a liberdade do sujeito para responder de acordo com sua lógica e conceitos. Também se seguiu a Hermenêutica Objetiva, de Övermann (1979), na qual se leva o sujeito estudado a expressar-se de forma reconstrutiva, buscando na particularidade do próprio sujeito uma compreensão esclarecida e crítica da realidade social. E ainda os pressupostos do método de Descrição Densa. de Geertz (1973), o qual vai além da técnica etnográfica, pois o que interessa não é apenas a interpretação ou explicação de fatos isolados, mas dos conjuntos que se constroem levando em consideração as diversas estruturas conceituais e significativas que moldam as ações humanas.

Seguindo princípios éticos da pesquisa com seres humanos, inicialmente foram apresentados, às comunidades estudadas, por meio do termo de consentimento livre e esclarecido (TCLE), os objetivos, finalidades e métodos das pesquisas. Bem como solicitado o consentimento para os registros imagéticos e áudios.

Os dados secundários aqui interpretados (AMORAS, 2017; ALVÃO, 2016; BARBOZA et al., 2018; BARBOZA et al., 2019) foram obtidos com base na aproximação participativa, ou seja, no acompanhamento e auxílio na realização de práticas cotidianas, com a preocupação de observar o ambiente e participar dos eventos sociais que ali se desenrolavam. Nesta etapa, era possível identificar os papeis de cada sujeito no grupo, e assim planejar a aplicação das demais técnicas, individualmente ou em Grupos Focais ${ }^{2}$. As memórias, acontecimentos e atividades relacionadas aos animais foram gravados em áudio (quando possível e consentido) ou registradas em formulários e diários de bordo. Os registros em áudio foram, posteriormente, transcritos com apoio do programa Listen $N$ Write Free 1.17.0.2. Os textos resultantes foram editados manualmente, quando necessário. Nestes textos, foi aplicada a análise de conteúdo ${ }^{3} \mathrm{de}$ acordo com Bardin (2011).

As técnicas de campo empregadas foram: (1) observação participante (CHIZZOTTI, 1995; QUEIRÓZ et al., 2011); (2) entrevistas baseadas em uma lista de tópicos previamente escolhidos, com enfoque "emicista-eticista" como proposto por Costa-Neto (2003) para a pesquisa etnozoológica; (3) lista livre de etnoespécies foram construídas, durante as entrevistas, à medida que cada domínio cultural foi trabalhado. Foram considerados como elementos culturalmente mais importantes, aqueles que apareceram em muitas listas e em uma ordem de importância semelhante, de acordo com Albuquerque e Lucena (2004); e ainda, quando pertinente, foram aplicadas as (4) técnicas projetivas com uso de fotografias de animais, da categoria taxonômica abordada por cada pesquisa, para confirmar as espécies às quais os agentes da pesquisa (pesquisador e pesquisados) se referiram nos momentos anteriores, sanando possíveis discrepâncias ${ }^{4}$.

\section{PESCADORES ARTESANAIS DA AMAZÔNIA COSTEIRA PARAENSE: AS COMUNIDADES ESTUDADAS}

A Amazônia é um bioma que se estende por uma grande porção da América do Sul, abrangendo partes de nove países. Com extensão de 8 milhões de $\mathrm{km}^{2}$, trata-se de uma área com

\footnotetext{
2 Seguindo a definição de Powell e Single (1996): um conjunto de pessoas selecionadas e reunidas por pesquisadores para discutir e comentar um tema, a partir de suas experiências pessoais.

${ }^{3}$ Um conjunto de técnicas de análise das comunicações, que utiliza procedimentos sistemáticos e objetivos de descrição do conteúdo das mensagens. Levando em conta a frequência dos temas extraídos do conjunto dos textos/fala, as representações dos conteúdos ou de suas expressões foram codificadas por recorte, agregação e enumeração de unidades de registro (palavras ou temas). As unidades de registro foram analisadas através das frequências e por análise temática da enunciação.

${ }^{4}$ De acordo com Frank (1939), as técnicas projetivas oferecem acesso ao mundo dos sentidos, significados, padrões e sentimentos, revelando aquilo que o sujeito não consegue expressar. Segundo Pinto (2014), a associação de palavras com estímulos visuais é útil para projetar as sensações e atitudes.
} 
alta diversidade de ecossistemas, alguns mais contrastantes (mata, cerrado, campinas, manguezal, costeiros) e outros de transição, por vezes muito sutis, na composição biótica da contínua área de floresta (AB'SABER, 2002). Parte dela está em contato com o Oceano Atlântico proporcionando uma extensa região amazônica costeira.

A costa amazônica compreende $35 \%$ dos, aproximadamente, $8.500 \mathrm{~km}$ da costa brasileira. As especificidades desse litoral, entre o rio Oiapoque no Amapá $\left(5^{\circ} \mathrm{N}, 51^{\circ} \mathrm{W}\right)$ e a baia de São Marcos no Maranhão $\left(2^{\circ} \mathrm{S}, 44^{\circ} \mathrm{W}\right)$, incluem precipitação anual elevada (até $3.300 \mathrm{~mm})$, temperaturas também elevadas $\left(>20{ }^{\circ} \mathrm{C}\right)$ com baixa variação anual, extensa plataforma continental (cerca de $330 \mathrm{~km}$ ), regime de macromarés (com valores máximos chegando a $6 \mathrm{~m}$ no Pará, $8 \mathrm{~m}$ no Maranhão, e $12 \mathrm{~m}$ no Amapá), descarga de dezenas de estuários e do maior rio do mundo (Amazonas) e elevado escoamento de sedimentos (nutrientes e matéria orgânica) (PEREIRA et al., 2009). Estas condições proporcionam o desenvolvimento de grande biodiversidade, bem como de uma ampla gama de modos de apropriação social, econômica e cultural dos ambientes costeiros.

A principal atividade produtiva dos moradores da costa amazônica é a pesca artesanal, definida por Diegues (2005) como "pequena pesca, cuja produção em parte é consumida pela família e em parte é comercializada.” As técnicas secularmente empregadas pelos indígenas serviram de base para a pesca nessa região, a qual é reconhecidamente uma atividade tradicional pela antiguidade de sua prática na Amazônia, pelos métodos e técnicas de captura, formas de acondicionamento e preparação do produto (FURTADO, 2006).

Segundo Furtado (1990), a pesca artesanal no Pará, abrange as pescarias flúvio-lacustres e costeiras ou marítimas (até 10 milhas do litoral paraense), e apresenta duas formas de organização social. Na forma polivalente, os pescadores se dedicam a várias atividades durante o ano, como roçados, extrativismo, coleta, criação de gado e pesca. Estes pescam para consumo próprio durante o ano e, sazonalmente, para comercialização. O elemento familiar predomina nas unidades de produção. Enquanto os pescadores monovalentes se dedicam às atividades de pesca durante todo o ano, tendo as parcerias como unidades de produção.

As comunidades de pescadores polivalentes onde os estudos foram realizados situamse na mesorregião nordeste paraense, na costa atlântica da Amazônia brasileira. Sendo quatro na/ou entorno da Reserva Extrativista Marinha (RESEX-MAR) Caeté-Taperaçu, uma na RESEX-MAR Tracuateua e uma na área onde se propõe a expansão das áreas de RESEX-MAR no município Salinópolis. Reservas Extrativistas são territórios de uso comum, regulamentadas com vistas à conservação dos recursos naturais, das culturas locais e meios de vida dos povos tradicionais. A regulação do uso dessas áreas é feita por cogestão, ou seja, gestão compartilhada entre a administração pública e os povos tradicionais, com princípios participativos. Para a implementação deste modelo de gestão, são criadas Associações de Usuários, como representantes do povo tradicional.

A Vila dos Pescadores estabeleceu-se na linha de praia, da península de Ajuruteua, no município de Bragança, ainda na segunda década do século XX. A forte erosão produzida pela variação no nível do mar apontada por Souza-Filho (2011), levou o governo local a construir uma nova vila com equipamentos urbanos (posto de saúde e escola), e induzir a transferência das famílias de pescadores artesanais para este novo local, situado próximo a um canal de maré. Entretanto, a formação da nova vila, denominada Bonifácio, em 1995, não extinguiu completamente a antiga Vila dos Pescadores. As vilas situam-se dentro dos limites da RESEXMAR Caeté-Taperaçu.

Também situada na RESEX-MAR Caeté-Taperaçu, as comunidades Castelo (dentro) e Taperaçu-Porto (entorno), se destacam por possuírem portos que permitem o atracamento de barcos de médio porte, importantes para a economia local, pois fornecem pescado para as 
empresas de processamento. Os pescadores dessas comunidades trabalham na costa da microrregião bragantina do Salgado, utilizando as ilhas como "rancho".

A comunidade Quatipuru-Mirim habita uma ilha que dista cerca de $40 \mathrm{~km}$ da sede do município de Tracuateua, onde pescam (peixe e camarão) para auto-sustento e comercialização durante o ano todo. É uma das três que se localizam dentro dos limites da RESEX-MAR Tracuateua, da qual são usuárias mais 55 comunidades localizadas no entorno da área. A qual situa-se contígua à oeste da RESEX-MAR Caeté-Taperaçu.

A comunidade de Santa Rosa localiza-se na área onde o Instituto Chico Mendes de Conservação da Biodiversidade/Ministério do Meio Ambiente propôs, em 2017, a implantação de uma nova RESEX-MAR no município de Salinópolis. Situada à margem direita do rio Urindeua, que corre do sul para o norte do município e deságua no Oceano Atlântico, esta comunidade possui energia elétrica, três estabelecimentos comerciais, uma igreja católica, um campo de futebol, uma escola municipal de educação básica, um posto de saúde e associação de moradores. O rio Urindeua, navegável apenas por pequenas embarcações, é de grande importância econômica para os moradores da Santa Rosa. As principais atividades das cerca de 35 famílias, são a agricultura familiar, a pesca e a coleta de caranguejo.

Os etnoconhecimentos de pescadores sobre tartarugas marinhas foram registrados nas comunidades Vila dos Pescadores e Vila Bonifácio (Bragança) (BARBOZA et al., 2018; BARBOZA et al., 2019). Sobre Maçaricos (Charadriiformes) na comunidade Santa Rosa (Salinópolis) (AMORAS, 2017). Sobre aves residentes e visitantes das Ilhas da microrregião bragantina - Canelas, Baiaco, Pilão e Quatipuru Mirim - foram escutados pescadores das comunidades Castelo e Taperaçu-Porto, e residentes na Cidade (Bragança); e ainda comunidade Quatipuru-Mirim (Tracuateua) (ALVÃO, 2016).

\section{ETNOZOOLOGIA: COMO OS ANIMAIS SÃO PERCEBIDOS PELOS PESCADORES}

A presença de tartarugas marinhas nas praias e águas continentais da microrregião bragantina foi descrita pela quase totalidade dos pescadores da Vila do Bonifácio e Vila dos Pescadores (península de Ajuruteua) que participaram da pesquisa.

As interações entre esses pescadores e as tartarugas marinhas ocorrem durante suas práticas pesqueiras (rede, curral e espinhel), e ainda em seus trajetos entre o mar e as comunidades. "[...] as redes de arrastão no fundo espanta as tartarugas, o que não malha nessas redes corre pra frente." Embora não percebam a temporalidade do processo reprodutivo das tartarugas marinhas, descrevem desovas da tartaruga-cinza e da aruanã (Chelonia mydas e Lepidochelys olivacea). "Tartaruga faz um rebaixo, arrudeio, para não cercarem os ovos, faz forçado marca." A adaptação aos ambientes costeiros é percebida pelos sabedores locais que distinguem os quelônios ${ }^{6}$ marinhos de outros grupos de ambientes dulcícolas e terrestres. "Aruanã tem a parte traseira cheia; Chimirra ${ }^{7}$ tem a parte traseira seca." Esta aguçada percepção de pescadores quanto à diversidade morfológica, fisiológica e comportamental também foi registrada para aves costeiras. Sendo o montante de informações sobre cada espécie bastante heterogêneo entre os pescadores artesanais que arrancham nas ilhas, o que indica diferentes graus de significância cultural de cada uma delas para este grupo social.

Os locais (ilhas Quatipurú-Mirim, Maciel, Baiaco, Canelas, Otelina, Carrapato e Ilha do Cachorro) e períodos de nidificação (entre os meses de maio a agosto) de diversas espécies foram claramente descritos.

\footnotetext{
${ }^{5}$ Denominação dada pelos pescadores a locais de apoio durante os longos períodos de pesca.

${ }^{6} \mathrm{O}$ grupo quelônios (Ordem Chelonia ou Testudinata) agrupa tartarugas, cágados e jabutis.

7 Quelônio de água doce, conhecido no Brasil como "cágado", na Amazônia, em geral, como "tartaruga da Amazônia".
} 
Os ninhos, geralmente localizam-se distante dos ranchos de pescadores e das casas, no caso de locais com residentes. Os pescadores classificam as aves quanto aos locais dos ninhos, dividindo-as em: aves que nidificam no chão (maçaricos, gaivotas) e as que nidificam sobre os galhos de árvores do manguezal (guará, galça, taquiri, maguari, entre outros). "Ah fíca lá em cima, lá em cima, eles fazem o linho lá em cima, lá em cima da siribeira do manguero..." Segundo os pescadores, várias mudanças nas áreas de nidificação relacionadas à geomorfologia das ilhas e perseguição de aves pelas pessoas estão ocasionando a diminuição de aves e de ovos nas ilhas de pesca. Os predadores dos ovos de aves mais citados pelos pescadores foram os cachorros, seguidos pelos gaviões, cobras e humanos. "Não ser uma praia muito 'habituada' num tem muita população, acho que devido também não ter energia elétrica, se tivesse, acho que só a iluminação espantava eles." Também na etnozoologia de pescadores no rio Urideua (na altura da comunidade Santa Rosa), é amplo o conhecimento sobre maçaricos. Observam, ao longo do ano, maior abundância dessas aves no período seco (denominado verão na região), ou seja, nos meses de julho a dezembro. Variações sazonais na diversidade também são percebidas. Há relatos de que somente o Maçariquinho (Actitis macularius) é presente durante todo o ano.

Nas narrativas dos pescadores, estas aves limícolas ${ }^{8}$ são avistadas diariamente alimentando-se, principalmente, do caranguejo-maracoanim, em praias e enseadas. Também em áreas de descanso, nos manguezais circundantes. Os principais predadores são o gaviãocaburé e as cobras.

Embora não seja o nosso objetivo aqui, confrontar os etnoconhecimentos sobre os animais com a zoologia científica, podemos afirmar que esta correlação é positiva. Ainda que construída e transmitida de formas diferentes da Ciência, como afirmam Santos-Fita e CostaNeto (2007), as etnozoologia locais nos fornecem o recorte de maior significância para os humanos que vivem em contato direto com os elementos naturais.

Este recorte agrega primor na tomada de decisões sobre ações que afetem os modos de vida das comunidades e povos tradicionais, na medida em que respeita o direito desses grupos sociais de serem ouvidos. Este direito foi preconizado na Convenção 169, da Organização Internacional do Trabalho (OIT), aprovada pela Organização das Nações Unidas em 1989. Esse Tratado Internacional sobre os direitos humanos de povos indígenas e tradicionais está em vigor no Brasil desde 2004 através do Decreto 5051 (BRASIL, 2004).

\section{ETNOTAXONOMIA: COMO OS PESCADORES CLASSIFICAM OS ANIMAIS}

Os pescadores listaram 26 etnoespécies de tartaruga-marinha, dentre as quais foi possível confirmar a presença das cinco espécies ocorrentes no litoral brasileiro (Ceará a Santa Catarina) pela ciência e nas políticas ambientais: tartaruga-amarela (Caretta caretta), tartarugacor-de-vinho (Eretmochelys imbricata), tartaruga-cinza (Chelonia mydas), aruanã (Lepidochelys olivacea) e tartaruga-de-couro (Dermochelys coriacea). Os caracteres diagnósticos neste sistema de classificação são morfológicos e comportamentais, tal qual a taxonomia ${ }^{9}$ zoológica clássica.

Estes mesmos aspectos são utilizados na etnotaxonomia de aves. A diversidade de aves é localmente organizada em um complexo sistema de classificação, baseado em atributos de formas, modos de vida e funcionalidade no ambiente. As espécies afins sendo reunidas em grupos, denominados por eles de "tipo" ou "marca" de aves, caracterizando os etnogêneros locais.

\footnotetext{
${ }^{8}$ Aves da Ordem Charadriiformes, geralmente associadas a zonas úmidas costeiras, como estuários e lagoas.

9 Taxonomia ou classificação biológica é uma ciência biológica que busca agrupar e categorizar as espécies de seres vivos (extintas e viventes).
} 
Segundo os pescadores das Ilhas, quarenta e cinco etnoespécies que residem ou visitam as ilhas da microrregião bragantina, sendo as mais citadas guará, galça, taquiri, gaivota e maçarico. Nas narrativas identificamos citações de variações nos caracteres de coloração, tamanho, tipo de bico e vocalização.

Dezessete etnoespécies de maçaricos foram citadas para as margens do rio Urindeua. As mais frequentes foram Maçaricão, Vira-pedra e Maçariquinho-da-beira-de-igarapé. Os pescadores locais utilizam para a distinção entre as etnoespécies as categorias locais classe, pinta e qualidades. "Eu faço porque tem as qualidades né, tem o grande, tem o menor e tem os que são pintadinho e outros que são diferente um do outro." Duas correntes teóricas foram propostas, inicialmente, para explicar os critérios utilizados nas classificações tradicionais (folk). A intelectualista ou cognitivista, defendida por Berlin et al. (1973), sugere que as pessoas classificam os organismos para satisfazer a necessidade inata de organizar o mundo à sua volta ou meramente por curiosidade. Enquanto a corrente utilitarista, proposta por Hunn (1977), afirma que as pessoas classificam os componentes do mundo natural que possuem valor para elas. Posteriormente, Atran (1998) propõe um modelo único de classificação, contemplando as duas correntes. Considera que os organismos são classificados em nível genérico com base em características culturais universais inatas. E que o nível específico está condicionado ao valor local dos seres naturais para as pessoas.

\section{INTERAÇÕES ENTRE PESCADORES E ANIMAIS}

O uso dos elementos da natureza pelos povos tradicionais evoluiu, a partir das necessidades para a sobrevivência, até o acúmulo de saberes através da observação e experimentação de fenômenos e características destes elementos. Os saberes acumulados favorecem e mantêm o conhecimento sobre os territórios, sendo necessário que se ressalte a importância da transmissão desses saberes às novas gerações. Assim, a biodiversidade deixa de ser apenas um conceito biológico, em relação a diversidade genética dos indivíduos, e dos ecossistemas, tornando-se o resultado de práticas milenares dessas comunidades. Este entendimento conduziu as chamadas etnociências ao interesse pela diversidade biológica, que também está ameaçada pela mundialização de modelos culturais dominantes (DIEGUES, 2000).

No estudo das tartarugas-marinhas registramos o aproveitamento de animais capturados acidentalmente para consumo de carne, bem como a coleta de ovos dos ninhos são descritos como hábitos alimentares esporádicos. Além do uso alimentar, os pescadores de Ajuruteua usam a banha e o casco da tartaruga para tratamento de dores em geral, asma e processos inflamatórios. E ainda, as cracas ${ }^{10}$ incrustadas no casco da tartaruga para "doenças dos olhos". Além do uso zooterápico, os moradores das Vilas Bonifácio e dos Pescadores também usam partes das tartarugas marinhas para confecção de zooartesanato, o que indica uma percepção estético-afetiva desses animais.

Quanto às interações humano-maçaricos, os pescadores admitiram consumir o maçarico como iguaria alimentar, mas afirmam que esse hábito foi abandonado por saberem que a caça de animais silvestres é ilegal ${ }^{11}$. Declaram reconhecimento da importância desses animais para o equilíbrio ambiental local e demonstram admiração contemplativa. Alguns relatam, com desaprovação, terem presenciado atitudes humanas de desprezo (balar, atirar e matar) para com os maçaricos.

Segundo Alves e Souto (2010), os conhecimentos acerca dos animais, transmitidos de geração em geração por tradição oral, são bem integrados com outros aspectos culturais. Sendo

\footnotetext{
${ }^{10}$ Animais da Classe Crustacea, infra-classe Cirripedia.

${ }^{11}$ A Lei n ${ }^{\circ} 5.197$, de 3 de janeiro de 1967, dispõe sobre a proteção à fauna e dá outras providências.
} 
resultado de inúmeras civilizações e tradições que se desenvolveram ao longo da história, os conhecimentos etnozoológicos são parte importante do patrimônio cultural humano.

\section{CONSIDERAÇÕES FINAIS}

A integração entre estudos etnozoológicos e levantamentos faunísticos é necessária quando o objetivo maior é a conservação da fauna em áreas habitadas por populações humanas.

A etnozoologia dos pescadores da Amazônia costeira paraense sobre tartarugasmarinhas e aves-costeiras revela que esses trabalhadores tradicionais produzem e transmitem conhecimentos, não apenas sobre aqueles grupos animais que utilizam como fonte de proteínas e de renda, mas sobre todos os animais que compõem o sistema onde vivem.

Os conhecimentos etnozoológicos, consistentes com a zoologia e a taxonomia zoológica de tartarugas-marinhas e aves-costeiras, constituem um conjunto de informações teóricopráticas que nos ajudam a conhecer a diversidade animal local, e deve ser considerado em planejamentos de ações sobre conservação e uso destes territórios.

As interações entre humanos e tartarugas-marinhas e humanos e aves aqui relatadas constituem-se em práticas sustentáveis, uma vez que não interferem no equilíbrio ambiental de forma significativa.

E ainda nota-se nas narrativas dos pescadores que suas práticas tradicionais evoluem de acordo com mudanças na sociedade. Tais como a promulgação de leis ambientais, que passam a ser consideradas por eles em suas atitudes junto aos elementos naturais.

\section{REFERÊNCIAS}

AB'SABER, Aziz N. Bases para o estudo dos ecossistemas da Amazônia brasileira. Estudos Avançados, v. 16, n. 45, p. 7-30, 2002.

ALBUQUERQUE, Ulysses Paulino; LUCENA, Reinaldo Farias Paiva. Métodos e técnicas para coleta de dados. In: ALBUQUERQUE, Ulysses Paulino; LUCENA, Reinaldo Farias Paiva. (Org.). Métodos e técnicas na pesquisa etnobotânica. Recife: Editora Livro Rápido /NUPEEA, 2004. p. 37-62.

ALVÃO, Alan Crhistian Quadros. Conhecimento ecológico local (CEL) de pescadores artesanais sobre aves limícolas na microrregião bragantina (Amazônia costeira, Brasil). 2016. Monografia (Licenciatura em Ciências Naturais) - Faculdade de Ciências Naturais, Universidade Federal do Pará, Bragança, 2016.

ALVES, R. R. N.; SOUTO, W. de M. S. Etnozoologia: conceitos, considerações históricas e importância. In: ALVES, R.R.N. et al. (org.). A Etnozoologia no Brasil: importância, status atual e perspectivas. Recife: NUPEEA, 2010. p. 21-40.

AMORAS, Camila Oscarina Correa. Ocorrências e conhecimento ecológico local sobre Maçaricos (Aves - Charadriiformes) no rio Urindeua (Vila de Santa Rosa, Salinópolis PA). 2017. Monografia (Licenciatura em Ciências Naturais) Faculdade de Ciências Naturais, Universidade Federal do Pará, Bragança, 2017.

ATRAN, Scott. Folk biology and anthropology of science: cognitive universals and cultural particulars. Behavioral and Brain Sciences. v. 21, p. 547-609. 1998. 
BARBOZA, Roberta Sá Leitão et al. Representações sociais acerca das tartarugas-marinhas de pescadores artesanais de Ajuruteua, Amazônia costeira, Bragança-Pará, Brasil.

Amazônica: Revista de Antropologia, v. 9, p. 458-480. 2018.

BARBOZA, Roberta Sá Leitão et al. Tartarugas-marinhas na costa amazônica paraense: ocorrências e representações sociais para pescadores artesanais. Cap. 6. In: OLIVEIRA, A. C. A interlocução de saberes na antropologia. Ponta Grossa: Atena Editora., 2019, p. 127144.

BARDIN, Laurence. Análise de conteúdo. São Paulo: Edições 70, 2011 rev. e amp.

BERKES, Fikret; COLDING, Johan; FOLKE, Carl. Rediscovery of traditional ecological knowledge as adaptive management. Ecological Applications, v. 10, n. 5, p. 12511262. 2000.

BERLIN, Brent; BREEDLOVE, Dennis E.; RAVEN, Peter H. General principles of classification and nomenclature in folk biology. American anthropologist, v. 75, n. 1, p. 214-242. 1973.

BRASIL. Decreto n. 6040 de 27 de fevereiro de 2007. Institui a Política Nacional de Desenvolvimento Sustentável dos Povos e Comunidades Tradicionais (PNPCT). Disponível em: http://www2.camara.leg.br/legin/fed/decret/2007/decreto-6040-7-fevereiro-2007-550693publicacaooriginal-66733-pe.html. Acesso em: 21 out. 2018.

BRASIL. Decreto 5051 de 19 de abril de 2004. Promulga a Convenção $n^{\circ} 169$ da Organização Internacional do Trabalho - OIT sobre Povos Indígenas e Tribais. Disponível em: http://www.planalto.gov.br/ccivil_03/_ato2004-2006/2004/decreto/d5051.htm. Acesso em: 12 out. 2020.

BROWN, Cecil H. The growth of ethnobiological nomenclature. Current Anthropology, v. 27, n. 1, p. 1-19. 1986.

CAMPOS, Marcio D’Olne. Fazer o Tempo e o 'Fazer do Tempo': ritmos em concorrência entre o ser humano e a natureza. Ciência \& Ambiente, v. 8, p. 7-33. 1994.

CHIZZOTTI, Antonio. Pesquisa em ciências humanas e sociais. São Paulo: Cortez, 1995.

COSTA-NETO, Eraldo Medeiros. Etnoentomologia no povoado de Pedra Branca, município de Santa Terezinha, Bahia. Um estudo de caso das interações seres humanos/insetos. 2003. 251p. Tese (Doutorado em Ecologia e Recursos Naturais) Universidade Federal de São Carlos, São Carlos, 2003.

DIEGUES, Antônio Carlos S. (Org.). Os saberes tradicionais e a biodiversidade no Brasil. São Paulo: MMA/COBIO/NUPAUB/USP, 2000.

DIEGUES, Antônio Carlos S. Aspectos sócio-culturais e políticos do uso da água. MMA, Plano Nacional de Recursos Hídricos. 2005. 15p. Disponível em: http://www. usp. br/nupaub/agua.pdf. Acesso em: 25 out. 2020.

ELLEN, R. F. Ethnobiology, cognition and the structure of prehension: some general 
theoretical notes. Journal of Ethnobiology, v. 6, n. 1, p. 83-98. 1986.

FRANK, Lawrence K. Projective Methods for the Study of Personality. Journal of Psychology: Interdisciplinary and Applied, v. 8, p. 389-413. 1939.

FURTADO, Lourdes Gonçalves. Características gerais e problemas da pesca amazônica no Pará. Boletim do Museu Paraense Emílio Goeldi, Série Antropologia. v. 6, n. 1. p. 41-93. 1990.

FURTADO, Lourdes Gonçalves. Origens pluriétnicas no cotidiano da pesca na Amazônia: contribuições para projeto de estudo pluridisciplinar. Boletim do Museu Paraense Emílio Goeldi. Ciências Humanas, v. 1, n. 2, p. 159-172. 2006.

GEERTZ, Clifford. Uma descrição densa: por uma teoria interpretativa da cultura. In: GEERTZ, Clifford. A Interpretação das Culturas. Rio de Janeiro: Guanabara Koogan, 1973. p. 13-41.

HUNN, Eugene. Tzeltal Folk Zoology: The Classification of Discontinuities in Nature. New York: Academic Press, 1977.

HUNTINGTON, Henry P. Using traditional ecological knowledge in science: methods and applications. Ecological applications, v. 10, n. 5, p. 1270-1274. 2000.

KELLERT, Stephen R. Affective, Cognitive, and Evaluative Perceptions of Animals. Cap.7. In: ALTMAN e cols. (eds.). Behavior and the Natural Environment. New York: Plenum Press, 1983. p. 241-267.

MARQUES, José Geraldo Wanderley. Aspectos ecológicos na etnoictiologia dos pescadores do complexo Mundau-Manguaba - Alagoas. 1991. Campinas. Tese (Doutorado em Ecologia) - Universidade Estadual de Campinas, Instituto de Biologia, Campinas, 1991.

MARQUES, José Geraldo Wanderley. O olhar (des) multiplicado. O papel da interdisciplinaridade e do qualitativo na pesquisa etnobiológica e etnoecológica. In: AMOROZO, M. C. de M.; MING, L. C.; SILVA. S. M. P. (Org.). Métodos de coleta e análise de dados em etnobiologia, etnoecologia e disciplinas correlatas. Rio Claro: UNESP/CNPq, 2002.

MATOS, Júlia Silveira; SENNA, Adriana Kivanski. História Oral como fonte: problemas e métodos. Historiae. v. 2, n. 1, p. 95-108. 2011.

ÖVERMANN, Ulrich et al. Die Methodologie einer "objektiven Hermeneutik" und ihrealgemeine forschungslogische Bedeutung in den Sozialwissenschaften. In: SÖFFNER, H. G. (Org.). Interpretative Verfahren in den Sozial- und Textwissenschaften. Stuttgart: Metzler, 1979. p. 352-434.

PEREIRA, Luci Cajueiro Carneiro et al. A Zona costeira amazônica brasileira. Revista de Gestão Costeira Integrada-Journal of Integrated Coastal Zone Management, v. 9, n. 2, p. 3-7. 2009. 
PINTO, Elza Rocha. Conceitos fundamentais dos métodos projetivos. Ágora, Rio de Janeiro, v. 17, n. 1, p. 135-153. 2014.

POSEY, Darrel Addison. Indigenous Knowledge and development: an ideological bridge to the future. Ciência e cultura, v. 35, n.7, p. 877-894. 1982.

POSEY, Darrel Addison. Etnobiologia: teoria e prática. In: Ribeiro D. (org.). Suma Etnológica Brasileira. Etnobiologia. Petrópolis: Vozes/Finep, v. 1, p. 15-25. 1986.

POWELL, Richard A.; SINGLE, Helen M. Focus groups. International Journal of Quality in Health Care. v. 8, n. 5, p. 499-504. 1996.

QUEIRÓZ, Danielle Teixeira; VALL, Janaina; SOUZA, Ângela Maria Alves; VIEIRA, Neiva Francenely Cunha. Observação participante na pesquisa qualitativa: conceitos e aplicações na área da saúde. Revista de Enfermagem da Universidade Estadual do Rio de Janeiro, v. 15, n. 2. p. 276-283. 2011.

RUEDIGER, M. A.; RICCIO, V. Grupo focal: método e análise simbólica da organização e da sociedade. In: VIEIRA, M. M. F.; ZOUAIN, D. M (Orgs.) Pesquisa qualitativa em administração. Rio de Janeiro: FGV. 2004. p. 25-35.

SANTOS-FITA, Dídac; COSTA-NETO, Eraldo Medeiros. As interações entre os seres humanos e os animais: a contribuição da etnozoologia. Biotemas. v. 20, n. 4, p. 99-110. 2007.

SCHEPS, Ruth. La science sauvage. Des saviors populaires auxethnoisciences. Paris:

Éditions du Seuil, 1993.

SOUZA-FILHO, Pedro Walfir Martins. Impactos naturais e antrópicos na planície costeira de Bragança (NE do Pará). In: PROST, M. T.; MENDES, A. C. (Org.). Ecossistemas costeiros: impactos e gestão ambiental. Belém: Museu Paraense Emílio Goeldi, 2001.

VARGAS CLAVIJO. Maurício; COSTA-NETO, Eraldo Medeiros. Actitudes hacia la fauna: algumas explicaciones de la conducta humana hacia los animales. In: ALVES. R.R; SOUTO, W.M.S.S; MOURÃO, J.S. (org.). A Etnozoologia no Brasil. v. IV. Recife: NUPEEA. 2010. 